\title{
Consumo voluntário e ingestão de nutrientes em Agapornis sp alimentados com ração comercial e sementes
}

\author{
OLIVEIRA, Júlia ${ }^{1}$; FERNANDES, Barbara ${ }^{1}$; MACHADO, Rodrigo ${ }^{2}$; MORENO, Tatiane ${ }^{3}$; ROCHA \\ Chayane $^{4}$
}

\footnotetext{
${ }^{1}$ Graduanda em Zootecnia, UFPR

${ }^{2}$ Graduando em Medicina Veterinária, UFPR

${ }^{3}$ Zootecnista, Mestranda do Programa de Pós-graduação em Zootecnia UFPR

${ }^{4}$ Professora do Departamento de Zootecnia, UFPR

E-mail: julia.caroline.oliveira203@gmail.com
}

RESUMO: Os psitacídeos em vida livre têm disponível grande variedade de alimentos na natureza, as suas escolhas alimentares baseiam-se na sabedoria nutricional obtida por meio de experiências ao passar das gerações, os tornando seletivos com sua alimentação, porém a alimentação de vida livre raramente é reproduzida em cativeiro. O objetivo deste trabalho foi analisar a ingestão voluntária e estimar a ingestão de nutrientes de dietas contendo ração e/ou sementes para Agapornis sp. Para tanto, 21 aves foram distribuídas em delineamento inteiramente casualizado em três tratamentos com sete repetições cada. Os tratamentos consistiram em: T1- ração extrusada (RE) + sementes de girassol (G), alpiste (A) e painço (P); T2- RE + A +P; T3- RE. O estudo teve duração de onze dias, sendo quatro de adaptação e sete de coleta de dados. Diariamente, foi disponibilizado para as aves $25 \%$ do peso corporal de cada item alimentar e, quantificado as sobras do comedouro e desperdício de alimentos. Para estimar a ingestão de nutrientes foram determinados em laboratório os teores matéria seca, de proteína bruta, extrato etéreo, cálcio e fósforo. Os dados de ingestão voluntária e ingestão de nutrientes foram submetidos à ANOVA e suas médias comparadas pelo Teste de Tukey (5\%). Verificou-se que as aves que receberam todos os itens alimentares (T1) ingeriram maior quantidade total de MS $(p<0,001)$ em relação ao T3. A ingestão de PB e EE foram maiores no T1 quando comparado aos T2 e T3. O consumo mínimo recomendado de $\mathrm{Ca}$ foi suprido somente nas aves que receberam apenas ração (T3) e diferiu dos T1 e T2. A ingestão de energia nas aves do T1 foi superior $(p<0,0001)$ em relação ao T2 e T3. Conclui-se que as aves preferiram a ingestão de sementes em relação a ração e tal comportamento refletiu na maior ingestão de matéria seca e, a exigência mínima de cálcio só foi suprida para as aves que tiveram acesso exclusivo a ração.

Palavras-chave: alimentação; girassol; nutrição.

\section{INTRODUÇÃO}

Os Agapornis sp. são psitacídeos de pequeno porte originários da África, sendo conhecidos como o "pássaro do amor" por serem muito calmos e afetuosos com aves da própria espécie, porém, apresentam comportamento territorialista. Caracterizam-se por ter um tamanho médio de $15 \mathrm{~cm}$, sua 
expectativa de vida é entre 10 a 12 anos, com faces em tons de vermelho, podendo ser mais claro ou escuro (variando assim do alaranjado ao rosado), apresenta olhos castanhos escuros, com o anel ocular de penas brancas. $\mathrm{Na}$ sua maioria não apresentam dimorfismo sexual (STIDHAM, 2006).

Os psitacídeos evoluíram com a variedade de alimentos disponíveis na natureza, as suas escolhas alimentares baseiam-se na sabedoria nutricional obtida por meio de experiências ao passar das gerações (REID e PERLBERG, 1998). A alimentação de psitacídeos de vida livre raramente é reproduzida em cativeiro, devido à grande quantidade de itens alimentares disponíveis, por isso a ingestão de nutrientes na natureza serve de parâmetro para a formulação de dietas em cativeiro (CARCIOFI, 2000). Contudo, a disponibilidade de ração comercial para aves ainda é muito pequena quando comparada ao consumo potencial, assim a oferta de rações não específicas e mistura de diversas sementes como alpiste, amendoim e girassol é muito comum (MACHADO \& SAAD, 2000) podendo ocasionar inúmeras doenças por desequilíbrio ou deficiência nutricional dos alimentos ingeridos, uma vez que os pássaros comem seletivamente (LUMEIJA et al. 1996).

Resta saber se a preferência dos psitacídeos é por alimentos considerados saudáveis para eles, como as rações extrusadas onde os nutrientes estão presentes de forma balanceada e própria para essas espécies, ou se a preferência é por alimentos mais palatáveis, como sementes. Dessa forma, objetivou-se quantificar o consumo voluntário e estimar a ingestão de nutrientes na espécie Agapornis sp. mantidos sob cuidados humanos e recebendo dietas contendo alimento completo comercial (ração) e diferentes tipos de sementes.

\section{MATERIAL E MÉTODOS}

O estudo foi realizado no Laboratório de Criação e Incubação de Animais Silvestres - LACRIAS, localizado na Fazenda Experimental da Universidade Federal do Paraná, com duração de onze dias, sendo quatro de adaptação e sete de coleta de dados. Para tanto, foram utilizados 21 Agapornis sp. adultos, distribuídos em delineamento experimental inteiramente casualizado com três tratamentos e sete repetições cada. As aves foram alojadas individualmente em gaiolas de arame galvanizado, medindo 0,60 x 0,50 x 0,50 $\mathrm{m}$. Em cada gaiola foram dispostos dois poleiros de madeira, comedouros de cerâmica e um bebedouro tipo nipple.

Os tratamentos consistiram em três dietas: $\mathrm{T} 1$ : ração extrusada para pscitacídeos de pequeno e médio porte em fase de manutenção (RE) + sementes de girassol $(G)$, alpiste $(A)$ e painço $(P)$; T2: RE + A + P; T3: RE. As aves foram pesadas no início e no final do experimento e, a quantidade diária ofertada de cada item alimentar foi estimada considerando $25 \%$ do peso corporal médio. Diariamente, foi disponibilizado para as aves $18,5 \mathrm{~g}$ de cada item alimentar em comedouros individualizados e, quantificado as sobras por comedouro e o desperdício da bandeja. Os itens alimentares (ração, alpiste, girassol e painço), bem como suas cascas foram separados e pesados individualmente.

Para estimar a ingestão total de matéria seca utilizou-se a expressão: ingestão $=$ ofertado - (sobras de comedouro + desperdício). Todos os alimentos fornecidos as aves foram analisados em laboratório para determinação dos teores de matéria seca, proteína bruta, extrato etéreo, matéria mineral, cálcio e fósforo 
segundo metodologia descrita pela AOAC (1995). A energia bruta foi determinada em bomba calorimétrica (Model 1261, Parr Instrument Co., Moline, IL) e a partir dos resultados estimou-se a ingestão de matéria seca, proteína bruta, extrato etéreo, cálcio e fósforo em gramas de nutriente/ave/dia. Para estimar a ingestão de nutrientes pelas aves, uma amostra de 100 gramas de cada semente ofertada às aves foi descorticada manualmente, possibilitando assim a quantificar a proporção entre conteúdo intracelular e cascas, analisar somente o material ingerido pelas aves e ajustar os cálculos de ingestão de nutrientes.

Os dados de ingestão voluntária e ingestão de nutrientes foram submetidos à análise de variância e suas médias comparadas pelo Teste de Tukey ao nível de 5\% de significância.

\section{RESULTADOS E DISCUSSÃO}

Devido ao hábito alimentar das aves de descascar as sementes antes da ingestão, o que será consumido é apenas o conteúdo interno da semente. Neste estudo em 100 gramas de girassol (casca e semente) verificou-se que a energia bruta (EB) foi de 6.591 $\mathrm{kcal} / \mathrm{kg}$, porém quando considerado apenas o conteúdo interno da semente, observou-se a EB de $7.350 \mathrm{kcal} / \mathrm{kg}$, apresentando alta concentração do extrato etéreo na semente inteira $(22,17 \%)$ e no conteúdo (36,07\%). Foi observado no painço o qual a semente (conteúdo+casca) apresentou 4.084 $\mathrm{kcal} / \mathrm{kg}$, enquanto 0 conteúdo apresentou $4.238 \mathrm{kcal} / \mathrm{kg}$. O alpiste possui valores elevados de cálcio e fósforo quando comparado a semente inteira $(0,21 \%-0,36 \%)$ com o conteúdo $(0,14 \%$ - 0,29\%), ao contrário das sementes inteira de girassol $(0,03 \%$ $0,13 \%)$ e painço $(0,13 \%-0,24 \%)$ que apresentam valores consideravelmente menores ao conteúdo $(0,19 \%-0,58 \%$ / $0,12 \%-0,31 \%)$.

Para aves de pequeno porte como os Agaponis que são mantidos em cativeiro, muitas vezes em gaiolas ou viveiros onde não exige grandes gastos de energia do animal, é necessário uma dieta bem elaborada, considerando a relação casca - conteúdo de uma semente para evitar problemas como obesidade e distúrbio nutricional.

Verificou-se que as aves que receberam todos os itens alimentares, ração+todas as sementes (T1) $(9,21$ $\mathrm{g} / \mathrm{dia}$ ) ingeriram maior quantidade total de MS $(p<0,001)$ quando comparadas ao tratamento composto somente por ração (T3) (6,16g/dia) como única opção de alimentação (gráfico 1 ).

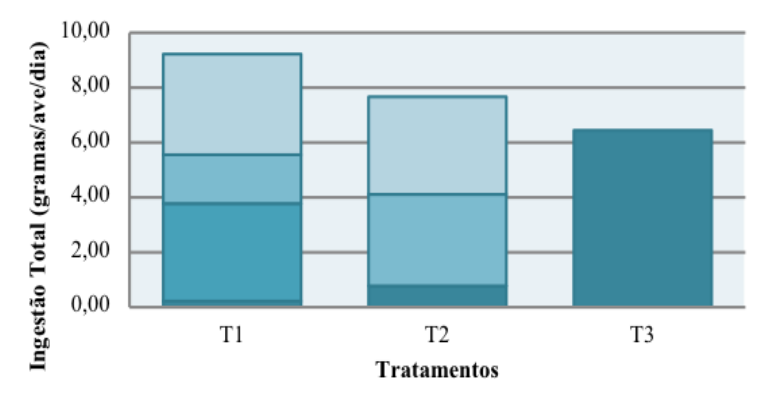

घRação घGirassol घPainço घAlpiste

Gráfico 1. Ingestão total de matéria seca (g/ave/dia) por item alimentar em Agapornis sp.

Foi possível observar que as aves apresentaram preferência por sementes em relação a ração e tal comportamento ocasionou na maior ingestão de matéria seca quando disponibilizou-se para as aves a oportunidade de escolha entre ração e/ou sementes, resultando em um consumo extremamente baixo de ração (Tabela 1).

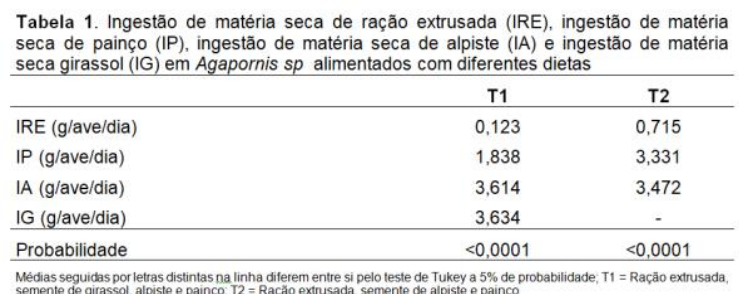


Conforme a tabela 2, a ingestão de $P B$ e EE foram significativamente maiores no tratamento com ração+todas as sementes quando comparado aos T2 e T3. O consumo mínimo recomendado de Ca foi suprido somente nas aves que receberam apenas ração (T3) $(0,061$ g/dia) e diferiu dos T1 e T2 (0,014; $0,020 \mathrm{~g} / \mathrm{dia})$. A ingestão de energia (50kcal/dia) nas aves do T1 foi superior $(p<0,0001)$ em relação ao T2 (32 $\mathrm{kcal} / \mathrm{dia})$ e T3 (27kcal/dia). Segundo as recomendações da AFFCO (1998) as exigências nutricionais para proteína bruta $(\mathrm{PB})$, cálcio $(\mathrm{Ca})$ e fósforo $(\mathrm{P})$ são de 12\% (mín), 0,30-1,20\% (mín-máx) e $0,30 \%$ (mín), respectivamente. Neste estudo, as aves ingeriram 14,36\%, $12,61 \%$ e $13,27 \%$ de proteína bruta e $0,15 \%, 0,20 \%$ e $0,99 \%$ de fósforo nos tratamentos 1, 2 e 3, respectivamente, atingindo a ingestão mínima recomendada para tais nutrientes. Entretanto, as aves apresentaram a ingestão de cálcio de 0,37\%, 0,66\% e $0,45 \%$ para os tratamentos 1,2 e 3 , respectivamente, atingindo a recomendação de ingestão mínima de cálcio somente no tratamento com fornecimento exclusivo de ração, conforme a tabela 3 .

\begin{tabular}{|c|c|c|c|c|}
\hline & $\mathrm{T} 1$ & T2 & T3 & $\mathrm{P}$ \\
\hline Ingestão MS' ${ }^{1}$ & $9,21^{\mathrm{a}}$ & $7,51^{\mathrm{ab}}$ & $6,16^{\mathrm{b}}$ & 0,009 \\
\hline Ingestão Proteína Bruta ${ }^{1}$ & $1,34^{\mathrm{a}}$ & $0,94^{b}$ & $0,82^{b}$ & 0,015 \\
\hline Ingestão Extrato Etéreo ${ }^{1}$ & $1,39^{\mathrm{a}}$ & $0,23^{b}$ & $0,64^{a b}$ & 0,017 \\
\hline Ingestão Cálcio ${ }^{1}$ & $0,014^{b}$ & $0,015^{\mathrm{b}}$ & $0,061^{\mathrm{a}}$ & $<0,0001$ \\
\hline Ingestão Fósforo ${ }^{1}$ & 0,035 & 0,021 & 0,027 & 0,055 \\
\hline Ingestão Energia' & $50,26^{\mathrm{a}}$ & $31,87^{\circ}$ & $27,05^{\mathrm{b}}$ & 0,005 \\
\hline
\end{tabular}
Tabela 3. Ingestão de proteina bruta (PB), Cálcio (Ca), Fósforo $(\mathrm{P})$ e a relação entre
Ca: $\mathrm{P}$ em cada tratamento em Agapornis sp recebendo diferentes dietas experimentais em comparação com as recomendações da AFFCO (1998)

\begin{tabular}{ccccc} 
em comparação com as recomendações da AFFCO (1998) \\
\hline T1 T2 T3 Recomendado Minimo* Recomendado Máximo*
\end{tabular}

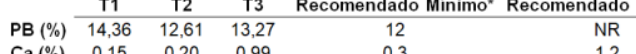
$\mathrm{Ca}(\%) \quad 0,15 \quad 0,20 \quad 0,99$

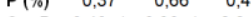
$\begin{array}{llll}\text { Ca: P } & 0,40: 1 & 0,30: 1 & 2,2: 1\end{array}$ 0,3 $1: 1$

\section{CONCLUSÃO}

Com os resultados obtidos nesse trabalho, foi possível observar que:
1) a disponibilidade de sementes possibilitou que as aves escolhessem os itens alimentares que preferiam consumir, resultando na maior ingestão de alimento;

2) o consumo de alpiste foi tão alto quanto o de girassol, o que não era esperado por não ser uma semente com alta concentração de lipídeos, demonstrando que a preferência dos Agapornis sp é por alimentos que sejam palatáveis a eles;

3) A exigência mínima de cálcio foi suprida somente quando as aves tiveram acesso exclusivo a ração.

\section{REFERÊNCIAS}

ABINPET - Associação Brasileira da Indústria de Produtos para animais de Estimação, Manual Pet Food Brasil $9^{\circ}$ edição. 2017.

BENEZ, S. M. Aves: criação, clínica, teoria, prática: silvestres, ornamentais, avinhados. 4. ed. Ribeirão Preto: Tecmedd, 2004. $600 p$.

LUMEIJA, J. T.; ZIJP, N. M. N.; SCHIPPERS, R. The acceptance of a recently introduced extruded parrot food in the Netherlands. Israel Journal of Veterinary Medicine, The Aviv, v. 51, n. 3/4, p.161 - 164, 1996.

MACHADO, P. A. R.; SAAD, C. E. P. O futuro das rações para aves ornamentais e silvestres no Brasil. Aves Revista Sul Americana de Ornitofilia, Belo Horizonte, v.3, p. 37-40, 2000.

STIDHAM T.A. (2006). Parrots (Aves: Psittaciformes) from the Miocene Varswater Formation, Langebaanweg, South Africa. Afr. Nat. Hist. 2, 198-199.

Agradecemos ao apoio da Fundação Araucária e da Coordenação de Aperfeiçoamento de Pessoal de Nível 
Superior - CAPES na realização do $3^{\circ}$ Workshop de Nutrição de Animais Selvagens.

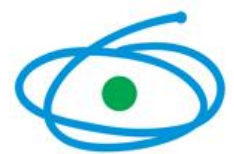

\section{CAPES}

PARANÁ

GOVERNO DO ESTADO Secretaria da Ciência, Tecnologia
e Ensino Superior

\section{FUNDACÃO \\ ARAUCARI}

Apoio ao Desenvolvimento Cientifico 